\title{
Intelligenty Work Zone System and Connected Vehicle Technologies to Reduce Crashes in Roadway Construction Area
}

\author{
Fengxiang Qiao*, Qing Li and Lei Yu \\ Texas Southern University, Houston, USA
}

Submission: July 24, 2017; Published: September 22, 2017

*Corresponding author: Fengxiang Qiao, Texas Southern University, 3100 Cleburne Street, Houston, TX, USA, Tel: (713) 313-1915;

Email: Qiao_FG@TSU.EDU

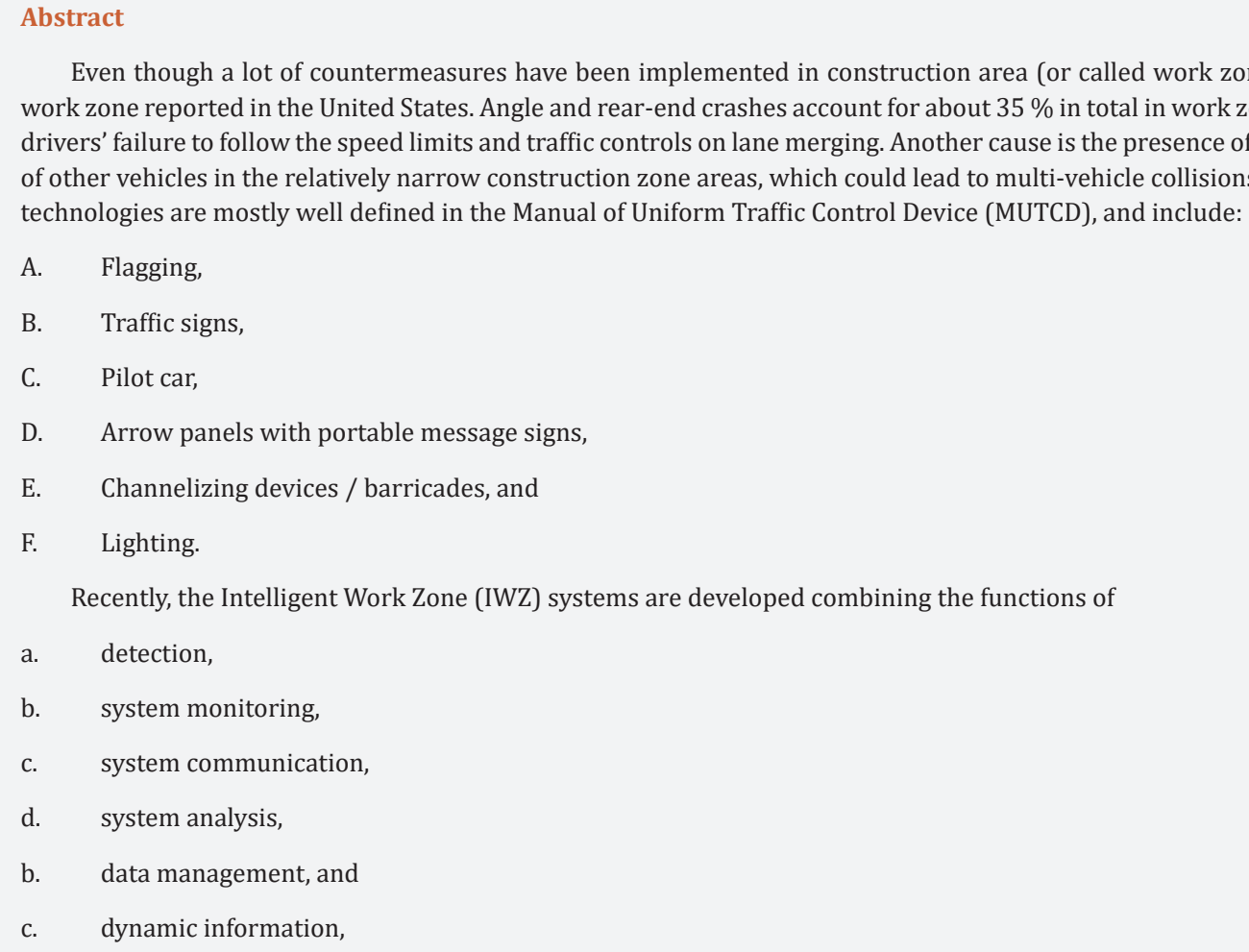
technologies are mostly well defined in the Manual of Uniform Traffic Control Device (MUTCD), and include:
A. Flagging,
B. Traffic signs,
C. Pilot car,
D. Arrow panels with portable message signs,
E. Channelizing devices / barricades, and
F. Lighting.

Recently, the Intelligent Work Zone (IWZ) systems are developed combining the functions of
a. detection,
b. system monitoring,
c. system communication,
d. system analysis,
b. data management, and
c. dynamic information,

Even though a lot of countermeasures have been implemented in construction area (or called work zone), there are still many crashes in work zone reported in the United States. Angle and rear-end crashes account for about $35 \%$ in total in work zones, the major causes of which are drivers' failure to follow the speed limits and traffic controls on lane merging. Another cause is the presence of large trucks that obstruct the sight of other vehicles in the relatively narrow construction zone areas, which could lead to multi-vehicle collisions. Conventional work zone warning

which is able to predict and provide motorists with real-time information (travel time, delay or speed) on a freeway work zone, so as to better inform motorists on all useful information.

The connected vehicle $(\mathrm{CV})$ technologies are developed to enable vehicles to communicate with each other and with the roadside infrastructure. The measures of effectiveness of the work zone warning system include the measurement of relevant operational factors, and the reduction in the occurrences of negative effects. It is recommended deploying and testing all possible intelligent technologies, especially the $\mathrm{CV}$ technologies for even smarter control of traffic movement in roadway work zone areas.

Keywords: Work zone; Construction area; Crashes; Construction area; Connected aehicle; Measurement of effectiveness

Abbreviations: MUTCD: Manual of Uniform Traffic Control Device; IWZ: Intelligent Work Zone;GES: General Estimates System; FARS: Fatality Analysis Reporting System; FHWA:Federal Highway administration; RTIS: Real Time Traveler Information Systems; QWS: Queue Warning Systems; IMS: Incident Management Systems ;VSLS: Variable Speed Limit Systems; AES: Automated Enforcement Systems; PMS: Performance Measurement Systems; CV: Connected Vehicle 


\section{Civil Engineering Research Journal}

Facts and Causes of Crashes in Roadway Work Zone Areas

During the period of roadway construction, a well designed construction area (or called work zone) is essential to (1) allow workers to execute missions within a safe working area, and (2) facilitate all types of road users (motorists, bicyclists, pedestrians) to safely proceed along temporarily assigned channels with reduced impacts on mobility and air quality. During peak seasons, approximately $20 \%$ of the nation's highway system is under construction (U.S.) NHTSA [1], and about 12 billion vehicle miles of travel each year will be through active work OSHA [2]. Due to the complicated situations and the lack of awareness by both the workers and road users in work zone areas, there are still a lot of work zone related fatal crashes, even though many treatments have been implemented in the refined layout design, enhanced traffic control and law enforcement. In 2015, a total of 700 people were killed in work zones, 138 of which were in State of Texas, ranking number one among all 50 states in the U.S. [3]. A variety of factors have been reported to work zone fatal crashes.

According to the work zone fatality data in General Estimates System (GES) and Fatality Analysis Reporting System (FARS) the top three contributing factors in 2014 in the U.S. include: (1) speeding, (2) lack of seatbelt use, and (3) alcohol driving, with 28\%, 25\%, and 25\%, respectively Traffic Safety Facts [4]. Twentythree percent of fatal work zone crashes occurred on urban interstates, and $20 \%$ occurred on urban arterials. Urban freeways and arterials account for $43 \%$ of all work zone fatal crashes though they account for only $5 \%$ of the mileage of the total roadway network USDOT [5]. Angle and rear-end crashes account for about $35 \%$ in total in work zones, the major causes of which are drivers' failure to Submitted to Civil Engineering Research Journal July 23, 2017 follow the speed limits and traffic controls on lane merging. Another cause is the presence of large trucks that obstruct the sight of other vehicles in the relatively narrow construction zone areas, which could lead to multi-vehicle collisions [6-9].

\section{Conventional Warning Methods to Enhance Work Zone Safety}

A typical work zone includes five areas: (1) advance warning area, (2) transition area, (3) buffer zone, (4) activity area, and (5) termination area. Most of the traffic control devices are placed in the advance warning area, while the conventioanl warning methods includes: (1) flagging, (2) traffic signs, (3) pilot car, (4) arrow panels with portable message signs, (5) channelizing devices / barricades and (6) lighting. These are all well defined in the Manual of Uniform Traffic Control Devices MUTCD [10].

When a one-lane two-way temporary traffic control zone is show enough to allow visibility from one end to another, traffic could be controlled by a flagger wearing high-visibility safety apparel and equipped with hand-held devices such as STOP/ SLOW paddles, and red flags. For most not-too-short work zones, various traffic signs (regulatory signs, warning signs, and guide signs) will be used to inform road users. Using traffic signs for internal construction worksite traffic control will assist workers to recognize the route they are to use at the construction site OSHA [11]. MUTCD [10] defines the minimum spacing of recommended advance warning signs. A pilot car may be used in a one-way, two- lane work zone to guide a queue of vehicles, the operation of which should be coordinated with other controls at each end of the work zone.

Arrow panels and portable changeable message signs usually contain luminous panels with high visibility that makes them an ideal traffic control supplement during both day and night. Huebschman et al. [12] argued that changeable message signs are actually no more effective than traditional message panels. The channelizing devices include cones, tubular markers, vertical panels, drums, barricades, and temporary raised islands, which can be used to warn road users of work zone condition and guide road users. Most channelizing devices were effective in alerting and guiding drivers [13].

However, the use of barricades in any combination of traffic control devices on urban multilane highways seemed to reduce the effectiveness of other traffic control devices [14]. Lighting devices are used based on engineering judgment to supplement retro-reflectorized signs, barriers, and channelizing devices. The four types of lighting devices commonly used in work zones are floodlights, flashing warning beacons, warning lights, and steadyburn electric lamps. Cottrell [15] reported that properly aimed and aligned lighting was able to avoid glare in nighttime work zone setup, thereby improving safety.

Intelligent Work Zone (IWZ) System and Connected Vehicle Technologies to Reduce Work Zone Crashes

The Intelligent Work Zone (IWZ) system combines the functions of

A. Detection,

B. System monitoring,

C. System communication,

D. System analysis,

E. Data management, and

F. Dynamic information [16].

The IWZ is able to predict and provide motorists with realtime information (travel time, delay or speed) on a freeway work zone, so as to better inform motorists on route choice, reduce their frustrations, reduce freeway congestion, and enhance safety for both road users and workers.

According to the Federal Highway Administration (FHWA) work zone implementation guide Ullman et al. [17], IWS can be classified into 7 categories:

a. Real-time traveler information systems (RTIS) to provide information on congestion, delay, and alternative route, 
b. Queue warning systems (QWS) to provide warnings to motorists on stopped or slow traffic to reduce the risk of rearend crashes,

c. Dynamic lane merge systems (DLMS) to dynamically instruct the motorists' merge actions to smooth merge maneuvers,

d. Incident management systems (IMS) to detect the occurrences of incidents for quick response,

e. Variable speed limit systems(VSLS) to dynamically adjust the speed limit to smooth traffic through work zones;

f. Automated enforcement systems (AES) to detect speeding vehicles and enforce the speed compliance of motorists, and

g. Performance measurement systems (PMS) to Submitted to Civil Engineering Research Journal July 23, 2017 evaluate the impact of the work zone based on quantitative measures.

The connected vehicle (CV) technologies are developed to enable vehicles to communicate with each other and the roadside infra structure, so that they have full-angle awareness of hazards and situations they cannot even see USDOT [18]. The CV technologies could dramatically improve safety in work zones by lessening the impact of human errors, and leading to less crashes, injuries and deaths [19].

The Dedicated Short-Range Communication (DSRC) based CV requires the participation of a broad community of stakeholders, such as state, and local transportation agencies, vehicle manufacturers, telecommunications providers, researchers, etc., which is a challenge in the history of the nation's transportation system AASHTO [20]. Significant potential benefits are expected to accrue through this effort NHTSA [21] including those in work zones Qiao, et al. [22]. Besides, the CV system could significantly reduce air pollutants and greenhouse gases as well for reduced fuel consumption and idling [23-26].

\section{Performance Measures of Crash Reduction Technologies in Work Zone}

Measures of effectiveness (MOEs) provide a quantitative basis for determining the effectiveness of work zone safety warning technologies. The required functions can be effectively determined by comparing "before" and "after" measurements of the MOEs, which shall be evaluated to ensure the effectiveness of the system in meeting its objectives and goals. The types of MOE may include: (1) the accuracy in measurement of traffic flow, variables, incident detection rate, mean detection time, false alarm rate, etc., and (2) reduction in the number of occurrences of congestion and queues, speeds, mean queue length, delays, the number of accidents/ severity of accidents, speed and advisory compliance, etc.

\section{Recommendations}

It is recommended deploying and testing all possible intelligent technologies, especially the $\mathrm{CV}$ technologies for even smarter control of traffic movement in roadway work zone areas. Successful innovative technologies (e.g., radar, bluetooth, Lidar, iCone device) could be prototyped to better detect traffic and construction vehicles, and better communicate with all road users and construction workers.

\section{Acknowledgement}

The authors acknowledge that this research is supported in part by the National Science Foundation (NSF) under grants \#1137732. The authors appreciate all test participants for their kind helps. The opinions, findings, and conclusions or recommendations expressed in this material are those of the author(s) and do not necessarily reflect the views of the funding agencies.

\section{References}

1. National Highway Traffic Safety Administration (NHTSA) (2017) Fatality Analysis Reporting System (FARS) Transportation injury mapping system (TIMS).

2. (2015) (OSHA) Occupational Safety and Health Administration.

3. (2017) National Work Safety Information clearing house.

4. Traffic Safety Facts (2013) A compilation of motor vehicle crash data from the Fatality Analysis Reporting System and the General Estimates System (GES).

5. US Department of Transportation USDOT (2014). Traffic Safety Facts 2013. Motor Vehicle Crashes: Overview.

6. Pigman DC Agent JG, KR (1990) Highway Accidents in Construction and Maintenance Work Zone. Transportation Research Record: Journal of the Transportation Research 1270, Washington, USA, pp. 12-21.

7. Schrock SD, Ullman GL, Cothron AS, Kraus E, Voigt AP (2004) An Analysis of Fatal Work Zone Crashes in Texas. FHWA/TX-05/0-4028-1. Texas Department of Transportation, USA.

8. Truck Safety Coalition (2014) Work Zone Truck Crash Dangers Fact Sheet.

9. Qiao F, Rahman R, Li Q Yu L (2016a) Identifying demographical effects on speed patterns in work zones using smart phone based audio warning message system. Journal of Ergonomics 6(153): 1-3.

10. Manual on Uniform Traffic Control Devices (MUTCD) (2009)Pedestrian and Worker Safety.

11. Occupational Safety and Health Administration OSHA (2005) Work Zone Traffic Safety.

12. Huebschman CR, Garcia C, Bullock DM, Abraham DM (2003) Construction Work Zone Safety. Report No. FHWA/IN/JTRP-2002/34 Purdue University, West Lafayette, Indiana. USA.

13. Pain RF, McGee HW, Knapp BG (1983) Evaluation of Traffic Controls for Highway Work Zones. National Cooperative Highway Research Program Report 236, Transportation Research Board, Washington, USA.

14. Garber NJ, Woo TH (1990) Accident Characteristics at Construction and Maintenance Zones in Urban Areas. Report No VTRC 90-R12. Virginia Transportation Research Council, Virginia, USA.

15. Cottrell BH (1999) Improving Night Work Zone Traffic Control. Research Report. Virginia Transportation Research Council, Charlottesville, Virginia, USA.

16. Minnesota Department of Transportation (MiDOT) Office of Traffic, Safety, and Operations (2008) Minnesota IWZ Toolbox Guideline for Intelligent Work Zone System Selection. 


\section{Civil Engineering Research Journal}

17. Ullman G, Schroeder J, Gopalakrishna D (2014) Use of technology and data for effective work zone management: Work zone ITS implementation guide. Technical Report FHWA- HOP-14- 008, Federal Highway Administration, Washington, USA.

18. US Department of Transportation (USDOT) (2017) How connected vehicles work.

19. Qiao F, Rahman R, Li Q Yu L (2016b) Identifying smart phone based intelligent messages for worker's crossing in work zones. Journal of Transportation Technologies 6(2): 76-85.

20. (2017) American Association of State Highway and Transportation Officials (AASHO), AASHTO Connected Vehicle Field Infrastructure Footprint Analysis.

21. National Highway Traffic Safety Administration (NHTSA) (2016) U.S DOT advances deployment of connected vehicle technology to prevent hundreds of thousands of crashes.

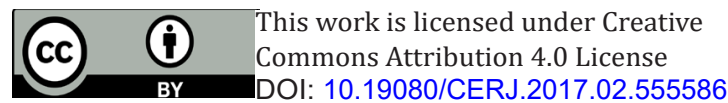

22. Qiao F, Jia J, Yu L, Li Q, Zai D (2014) Drivers Smart Assistance System Based on Radio Frequency Identification: Enhanced Safety and Reduced Emissions in Work Zones Transportation Research Record: Journal of the Transportation Research Board 2458: 37-46.

23. Texas A \& M Transportation Institute (TTI) (2012) Urban Mobility Report.

24. Li Q Qiao F, Yu L (2016) Vehicle Emission Implications of Drivers Smart Advisory System for Traffic Operations in Work Zones. Journal of Air \& Waste Management 66(5): 446-455.

25. Qiao F, Rahman R, Li Q, Yu L (2016c) Safe and Environment-Friendly Forward Collision Warning Messages in the Advance Warning Area of a Construction Zone. International Journal of Intelligent Transportation Systems Research 15(3): 166-179.

26. Habermann J (2015) I-35 smart work zone update. Texas Department of Transportation Short Course Slides.

\section{Your next submission with Juniper Publishers will reach you the below assets}

- Quality Editorial service

- Swift Peer Review

- Reprints availability

- E-prints Service

- Manuscript Podcast for convenient understanding

- Global attainment for your research

- Manuscript accessibility in different formats

( Pdf, E-pub, Full Text, Audio)

- Unceasing customer service

Track the below URL for one-step submission https://juniperpublishers.com/online-submission.php 